\title{
Baicalin inhibits PDGF-BB-induced hepatic stellate cell proliferation, apoptosis, invasion, migration and activation via the miR-3595/ACSL4 axis
}

\author{
XIONGJIAN WU, FACHAO ZHI, WEIJIAN LUN, QILIANG DENG and WENDI ZHANG
}

\begin{abstract}
Guangdong Provincial Key Laboratory of Gastroenterology, Institute of Gastroenterology of Guangdong Province, Department of Gastroenterology, Nanfang Hospital, Southern Medical University, Guangzhou, Guangdong 510515, P.R. China
\end{abstract}

Received February 5, 2017; Accepted December 22, 2017

DOI: $10.3892 / \mathrm{ijmm} .2018 .3427$

\begin{abstract}
Hepatic fibrosis is a physiological response to liver injury that includes a range of cell types. The pathogenesis of hepatic fibrosis currently focuses on hepatic stellate cell (HSC) activation into muscle fiber cells and fibroblasts. Baicalin is a flavone glycoside. It is the glucuronide of baicalein, which is extracted from the dried roots of Scutellaria baicalensis Georgi. Previous work focused on the anti-viral, -inflammatory and -tumor properties of baicalin. However, the potential anti-fibrotic effects and mechanisms of baicalin are not known. The present study demonstrated that baicalin influenced the activation, proliferation, apoptosis, invasion and migration of platelet-derived growth factor-BB-induced activated HSC-T6 cells in a dose-dependent manner. To investigate the anti-fibrotic effect of baicalin, a one-color micro (mi)RNA array and reverse transcription-quantitative polymerase chain reaction analyses were used. Results demonstrated that baicalin increased the expression of the miRNA, miR-3595. In addition, the inhibition of miR-3595 substantially reversed the anti-fibrotic effect of baicalin. The present data also suggested that miR-3595 negatively regulates the long-chain-fatty-acid-CoA ligase 4 (ACSL4). Furthermore, ACSL4 acted in a baicalin-dependent manner to exhibit anti-fibrotic effects. Taken together, it was concluded that baicalin induces miR-3595 expression that modulates the expression levels of ACSL4. To the best of our knowledge, the present study is the first to demonstrate that baicalin induces overexpression of human miR-3595, and subsequently decreases the expression of ACSL4, resulting in an anti-fibrotic effect.
\end{abstract}

Correspondence to: Professor Fachao Zhi, Guangdong Provincial Key Laboratory of Gastroenterology, Institute of Gastroenterology of Guangdong Province, Department of Gastroenterology, Nanfang Hospital, Southern Medical University, Guangzhou, Guangdong 510515, P.R. China

E-mail: zhifc41532@163.com

Key words: hepatic fibrosis, baicalin, miR-3595, long-chain-fattyacid-CoA ligase 4

\section{Introduction}

Hepatic fibrosis, a spontaneous wound healing response, occurs when the liver has an acute or chronic injury caused by viral infection, drug damage or immune attack $(1,2)$. Fibrosis impairs tissue and organ function and is caused by excessive deposition of the extracellular matrix (ECM) that occurs as a result of inflammation $(3,4)$. Liver fibrosis markedly contributes to morbidity in patients with liver disease (5). Hepatic stellate cells (HSCs) are pivotal in the development of hepatic fibrosis (6) and have the ability to proliferate and differentiate into myofibroblast-like cells (7). Platelet-derived growth factor (PDGF) signaling is one of the best characterized pathways of HSC activation (8) and induces apoptosis, senescence or quiescence in HSCs (9). Thus, inhibiting the activation of HSCs may be a feasible therapeutic strategy for hepatic fibrosis.

Various agents, including malotilate, genistein, curcumin and silymarin, have been reported to be effective against fibrosis in vitro and in vivo $(10,11)$; however, none of these are ideal candidates for inhibiting the activation of HSCs. Currently, an increasing number of natural products derived from herbal extracts are used in the treatment of diseases such as liver fibrosis; however, the different mechanisms through which they work are not known (12). Baicalin (Fig. 1), is the major bioactive flavonoid extracted from dried roots of the herb Scutellaria baicalensis Georgi (13). Baicalin exhibits a range of pharmacological effects that include antioxidative, anti-viral, and anti-inflammatory properties, as well as liver protection (14). Previous reports have indicated that baicalin has significant anti-fibrogenic effects that act by suppressing the signaling of canonical Wnts $(15,16)$. Baicalin also inhibits hepatic fibrosis by reducing the level of pro-fibrotic cytokines, including transforming growth factor (TGF)- $\beta 1$, tumor necrosis factor- $\alpha$, interleukin (IL)- 6 and IL-22. The reduction of these cytokines significantly enhances HSC senescence or apoptosis and reduce the activation of HSCs $(17,18)$. To expand the application of baicalin, it is necessary to further elucidate the mechanisms of the anti-fibrotic effect of baicalin.

MicroRNA (miRNA) are short RNA molecules ( 22 nucleotides) (19) that typically bind to the 3 ' untranslated region (3'UTR) of specific mRNA to regulate gene expression, either 
by repressing mRNA translation or promoting repression. They are involved in diverse physiological and developmental processes $(20,21)$ and regulate all biological processes in all cell types, such as cells in the liver. Previous research suggests that miRNA are involved in the regulation of HSC activation (7). Thus, modulating miRNA represents a novel therapeutic approach for hepatologists in the treatment of liver disease.

Long-chain-fatty-acid-CoA ligase 4 (ACSL4) is a member of the long-chain acyl-CoA synthetase (ACSL4) family that preferentially uses arachidonate and eicosapentaenoate as substrates, and activates long-chain fatty acids for the synthesis of cellular lipids $(22,23)$. ACSL4 is associated with various liver diseases (24) and is aberrantly regulated in liver cancer (25).

The present study demonstrated the anti-fibrogenic property of baicalin in PDGF-BB-induced HSCs. miRNA profiles of PDGF-BB-induced activated HSC-T6 cells treated with and without baicalin were compared. Results indicated that miR-3595 was upregulated in baicalin-treated cells compared with the levels in the untreated cells. It was also revealed that ACSL4 is a potential functional target of miR-3595. These findings indicate the central role of baicalin in inhibiting the activation of HSCs and suggest that baicalin has the potential to be an effective natural medicine for the treatment of hepatic fibrosis. The present results support ongoing research to identify potential therapeutic targets for liver fibrosis.

\section{Materials and methods}

Cell culture and treatment. HSC-T6 cells were purchased from American Type Culture Collection (Manassas, VA, USA) and were cultured in Dulbecco's modified Eagle medium (DMEM; cat. no. 11965-092; Invitrogen; Thermo Fisher Scientific, Inc., Waltham, MA, USA) supplemented with $10 \%$ fetal bovine serum (FBS; cat. no. 10099-141; Invitrogen; Thermo Fisher Scientific, Inc.). The cells were grown in a humidified atmosphere maintained at $5 \% \mathrm{CO}_{2}$ at $37^{\circ} \mathrm{C}$. The cells were serum-starved in an FBS-free medium for $24 \mathrm{~h}$ and then induced with PDGF-BB (10 ng/ml; cat. no. P3201; Sigma-Aldrich; Merck KGaA, Darmstadt, Germany), following the protocol in a previous study (26). The cells were treated with baicalin at different concentrations (50, 100 and $150 \mu \mathrm{M}$; cat. no. 572667; Sigma-Aldrich; Merck KGaA) for the indicated time according to different experiments at $37^{\circ} \mathrm{C}$. The same volume of diluted dimethyl sulfoxide (DMSO) was used as a negative control. While the baicalin stock solution was in DMSO, it was ensured that the concentration of DMSO did not influence cell survival. Plasmids [ACSL4 wild-type (WT) and mutant (MUT); constructed by Shanghai GenePharma Co., Ltd., Shanghai, China] and miR-3595 inhibitors (5'-AUCGUAGAG GAAAAUCCAC-3') or negative control (NC; 5'-CAGUAC UUUUGUGUAGUACAA-3') (Shanghai GenePharma Co., Ltd.) were transfected into cells using Lipofectamine ${ }^{\circledR} 2000$ (cat. no. 11668027; Invitrogen; Thermo Fisher Scientific, Inc.) at a concentration of $50 \mathrm{nM}$, following the manufacturer's instructions. After $48 \mathrm{~h}$ of transfection, cells were treated with different reagents for different experiments.

Cell proliferation assay. The induced HSC-T6 cells $\left(1 \times 10^{4}\right.$ cells/well) were seeded into 96 -well plates and

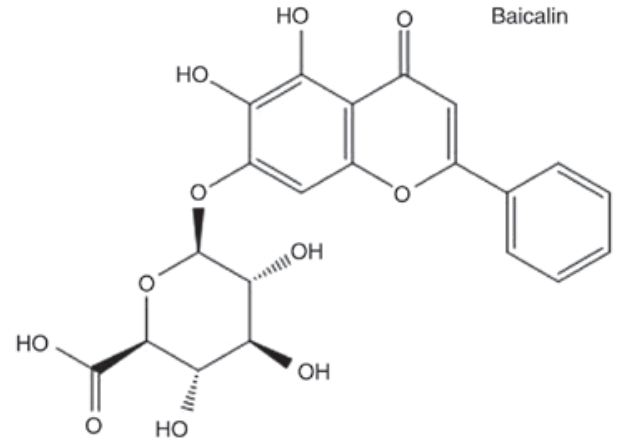

Figure 1. Chemical structure of baicalin.

treated with baicalin for $72 \mathrm{~h}$ at $37^{\circ} \mathrm{C}$. Cell proliferation was assessed using a Cell Counting Kit-8 (CCK-8) assay (cat. no. 96992; Sigma-Aldrich; Merck KGaA), according to the manufacturer's protocol. The optical density was measured at $450 \mathrm{~nm}$.

RNA isolation and reverse transcription-quantitative polymerase chain reaction ( $R T-q P C R)$. Total RNA from HSC-T6 cells was extracted using TRIzol reagent (cat. no. 15596026; Invitrogen; Thermo Fisher Scientific, Inc.), according to the manufacturer's protocol. Total RNA was reverse-transcribed to cDNA by using a Bestar qPCR RT kit (cat. no. 210212; Qiagen GmbH, Hilden, Germany) following the manufacturer's protocol. Following this, cDNA was quantified by qPCR on a Mx3000p real-time PCR system with DBI Bestar ${ }^{\circledR}$ SYBRGreen qPCR master mix (cat. no. DBI-2073; DBI Bioscience, Ludwigshafen, Germany) in a $20-\mu 1$ PCR reaction. qPCR was performed using the following settings: Pre-denaturation at $95^{\circ} \mathrm{C}$ for $10 \mathrm{sec}$, followed by 40 cycles of denaturation at $95^{\circ} \mathrm{C}$ for $10 \mathrm{sec}$ and elongation at $60^{\circ} \mathrm{C}$ for $30 \mathrm{sec}$. Results were normalized to $\beta$-actin expression. The $2^{-\Delta \Delta \mathrm{Cq}}$ method was used for calculating the relative expression levels (27). The PCR primer sequences are listed in Table I.

Western blot analysis. Cells were lysed with radioimmunoprecipitation assay buffer (cat. no. R0278; Sigma-Aldrich; Merck KGaA) supplemented with protease inhibitor cocktail (cat. no. ab201111; Abcam, Cambridge, UK) for 30 min on ice. The protein concentration was determined using a Bio-Rad protein assay kit (cat no. 5000002; Bio-Rad Laboratories, Inc., Hercules, CA, USA). A total of $20 \mu \mathrm{g} /$ lane protein was separated on $10 \%$ SDS-PAGE and transferred to a polyvinylidene difluoride membrane. The membranes were blocked with $5 \%$ skim milk for $1 \mathrm{~h}$ at room temperature. The membranes were incubated overnight with the following specific primary antibodies: $\alpha$-smooth muscle actin (SMA; 1:1,000; cat. no. A5228; Sigma-Aldrich; Merck KGaA), collagen (Col) I (1:1,000; cat. no. NB600-408; Novus Biologicals, LLC, Littleton, CO, USA), Col III (1:1,000; cat. no. ab6310; Abcam), TGF- $\beta 1$ (1:1,000; cat. no. ab92486; Abcam), desmin (1:1,000; cat. no. ab8592; Abcam), GAPDH (1:4,000; cat. no. 14C10; Cell Signaling Technology, Inc., Danvers, MA, USA) and ACSL4 (1:1,000; cat. no. sc-365230; Santa Cruz Biotechnology, Inc., Dallas, TX, USA) at $4{ }^{\circ} \mathrm{C}$. Following this, incubation was 
Table I. Primer sequences used for microRNA and mRNA expression analysis.

\begin{tabular}{|c|c|c|}
\hline Primer & Sequence $\left(5^{\prime}-3^{\prime}\right)$ & Length, bp \\
\hline$\beta$-actin $\mathrm{F}$ & GGAGATTACTGCCCTGGCTCCTA & 150 \\
\hline$\beta$-actin R & GACTCATCGTACTCCTGCTTGCTG & \\
\hline miR-3595 reverse transcription & CTCAACTGGTGTCGTGGAGTCGGCAATTCAGTTGAGATCGTAGA & \\
\hline miR-3595 F & ACACTCCAGCTGGGGTGGATTTTCCTCTA & \\
\hline All $\mathrm{R}$ & CTCAACTGGTGTCGTGGA & \\
\hline ACSL4 F & AAGGAGAAGGGCAAAGAGA & 211 \\
\hline ACSL4 R & GGTGGTTGTAGGAGGCTGA & \\
\hline
\end{tabular}

F, forward; R, reverse; ACSL4, long-chain-fatty-acid-CoA ligase 4; All R, reverse primer for miRNA qPCR.

performed with horseradish peroxidase-conjugated secondary immunoglobulin antibodies (1:10,000; cat. no. A4416 and A6154; Sigma-Aldrich; Merck KGaA) for $1 \mathrm{~h}$ at room temperature. Enhanced chemiluminescence chromogenic substrate (cat. no. 32109; Invitrogen; Thermo Fisher Scientific, Inc.) was used and signals were recorded on an X-ray film. $\beta$-actin was chosen as the loading control.

Cell invasion and motility assay. A cell migration assay was performed using Transwell chambers containing $8-\mu \mathrm{m}$ pore size filters. For the invasion assay, the inserts were coated with thin Matrigel.A total of $6 \times 10^{4} \mathrm{HSC}-\mathrm{T} 6$ cells in $200 \mu \mathrm{FBS}$-free medium were added to each upper chamber. A total of $500 \mu \mathrm{l}$ DMEM supplemented with $10 \%$ FBS was added to the lower chamber as a chemoattractant. Following incubation for 24 and $36 \mathrm{~h}$ at $37^{\circ} \mathrm{C}$, the cells that migrated through the filter pores were fixed with $70 \%$ ethanol at room temperature for $20 \mathrm{~min}$ and stained with crystal violet for $10 \mathrm{~min}$ at room temperature. The results were calculated from five random fields under a light microscope (magnification, $\mathrm{x} 400)$.

Cell cycle analysis. The cells were trypsinized, collected by centrifugation at $300 \mathrm{x}$ g for $5 \mathrm{~min}$ at room temperature and washed with PBS. The harvested cells were subsequently fixed in pre-cooled $70 \%$ ethanol, and stored at $4^{\circ} \mathrm{C}$ overnight. The cells were then washed with PBS and treated with DNase-free RNase (cat. no. 11119915001; Sigma-Aldrich; Merck $\mathrm{KGaA}$ ) and stained with propidium iodide in the dark for $15 \mathrm{~min}$ at room temperature. Cell samples were analyzed by using a FACSCalibur (BD Biosciences, Franklin Lakes, NJ, USA).

Analysis of apoptosis. The cells were trypsinized and collected by centrifugation at $300 \mathrm{x} \mathrm{g}$ for $5 \mathrm{~min}$ at room temperature. The harvested cells were washed with PBS and stained with annexin V-fluorescein isothiocyanate and propidium iodide (PI; cat. no. 556547; BD Biosciences), according to the manufacturer's protocol. Cell samples were analyzed using a flow cytometer within $1 \mathrm{~h}$ of staining. The results were analyzed by FlowJo version 10 (BD Biosciences).

miRNA microarray. The total RNA extracted using TRIzol was purified and RNA quality was assessed using a NanoDrop
ND-1000 (Thermo Fisher Scientific, Inc., Wilmington, DE, USA). miRNA array experiments were conducted, according to the manufacturer's instructions. Total RNA was labeled using a miRCURY ${ }^{\mathrm{TM}}$ Array Power Labeling kit (cat. no. 208500; Exiqon A/S, Vedbaek, Denmark). An Axon GenePix 4000B microarray scanner (Molecular Devices, LLC, Sunnyvale, CA, USA) was utilized to obtain the scanning profiles. Following normalization, the statistical significance of differentially expressed miRNA was analyzed by a Student's t-test (GraphPad Prism 5; GraphPad Software, Inc., La Jolla, CA, USA).

Plasmid construction. To overexpress ACSL4, full-length Homo sapiens ACSL4 sequences from the National Center for Biotechnology Information database (Gene ID: 2182; ncbi.nlm.nih.gov/nuccore/NM_001318510.1) were cloned into the pcDNA3.0 vector (cat. no. V790-20; Invitrogen; Thermo Fisher Scientific, Inc.). To generate the luciferase reporter plasmid, the 3'UTR of WT ACSL4 was cloned into the pLUC vector (cat. no. 42094; Addgene, Inc., Cambridge, MA, USA). Mutations in the 3'UTR of the WT ACSL4 were designed for four nucleotides (AAAUCC to ACGUAA) of the 6-mer seed region of the putative binding site of miR-3595 (pLUC-MUT-UTR). All DNA constructs were sequenced.

Dual-luciferase reporter assay. The luciferase reporter plasmid pLUC was purchased from Addgene, Inc., (cat. no. 42094). For the dual-luciferase assay, HSC-T6 cells were transiently transfected with either the pLUC-WT-UTR plasmid or the pLUC-MUT-UTR plasmid and miR-3595 mimics or control NC mimics using Lipofectamine ${ }^{\circledR} 2000$. After 48 h, cells were washed with PBS, lysed with lysis buffer and luciferase activity was measured by using the Dual-Luciferase Reporter Assay kit (cat. no. E1910; Promega Corporation, Madison, WI, USA). Results were normalized to Renilla luciferase activity.

miRNA targets mRNA prediction. Target mRNA of miRNA were identified using the following two websites: microRNA.org and targetscan.org.

Statistical analysis. Data were presented as the mean \pm standard deviation. Statistical analyses were performed using SPSS 17.0 (SPSS, Inc., Chicago, IL, USA) in all the pertinent experiments. Differences between groups were analyzed using the 
A

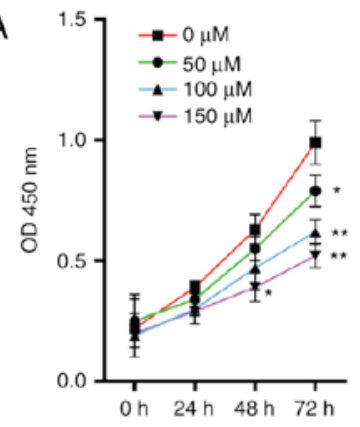

B

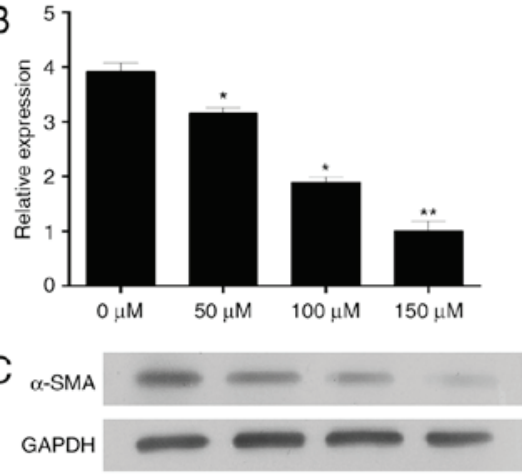

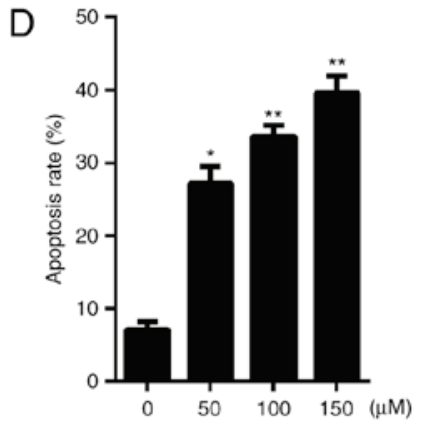

E

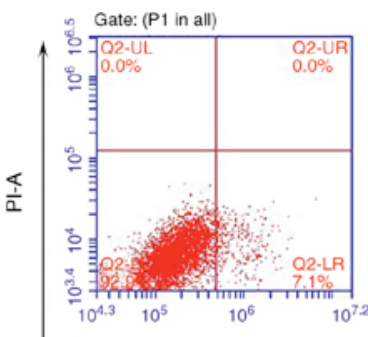

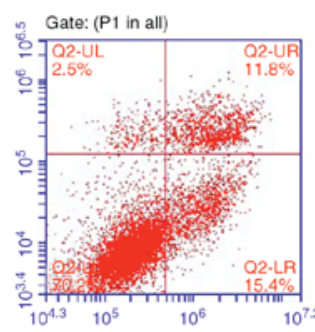

Annexin V FITC-A
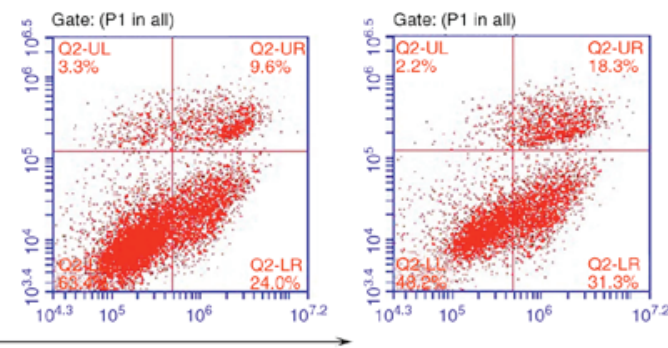

$\mathrm{F}$

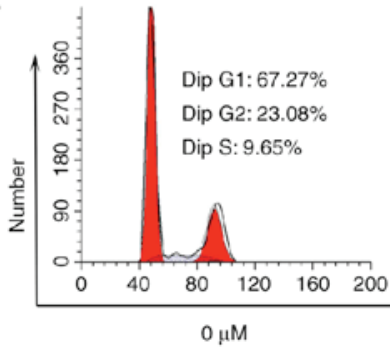

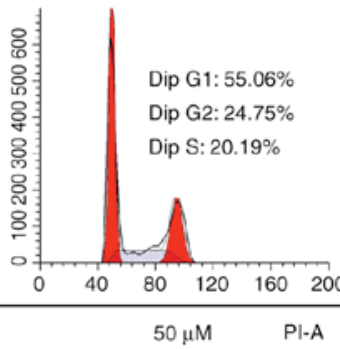

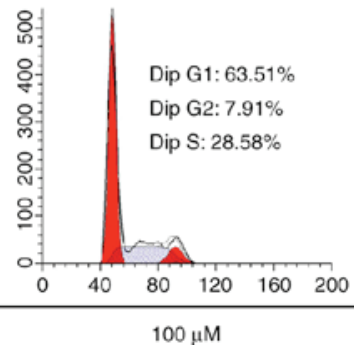

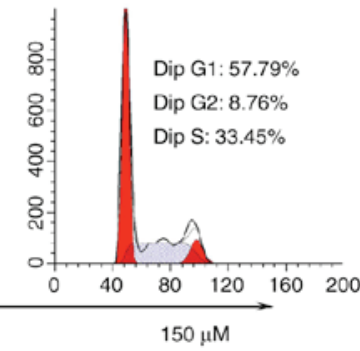

Figure 2. Baicalin inhibits the proliferation and activation and increases the apoptosis of PDGF-BB-induced HSC-T6 cells. PDGF-BB-induced HSC-T6 cells were treated with baicalin at different concentrations $(0,50,100$ or $150 \mu \mathrm{M})$. (A) A Cell Counting Kit- 8 assay was used to determine cell proliferation every $24 \mathrm{~h}$ for 3 days. The expression levels of $\alpha$-SMA (B) mRNA and (C) protein were determined by reverse transcription-quantitative polymerase chain reaction and western blotting, respectively. (D and E) The apoptosis rate of HSC-T6 cells was measured by flow cytometry. (F) The effect of baicalin on the cell cycle in PDGF-BB-induced HSC-T6 cells was determined. "P $<0.05$ and ${ }^{* *} \mathrm{P}<0.01$ vs. untreated cells. PDGF, platelet-derived growth factor; $\alpha$-SMA, $\alpha$-smooth muscle actin; PI, propidium iodide; FITC, fluorescein isothiocyanate; OD, optical density.

Student's t-test or one-way analysis of variance followed by a Tukey's test. $\mathrm{P}<0.05$ was considered to indicate a statistically significant difference.

\section{Results}

Baicalin inhibits the proliferation, activation, apoptosis and cell cycle progression of activated HSC-T6 cells induced by $P D G F-B B$. The present study aimed to determine the effect of baicalin on cell proliferation and survival. Activated HSC-T6 cells were treated with different concentrations of baicalin $(50,100$ or $150 \mu \mathrm{M})$ for $72 \mathrm{~h}$. A CCK-8 assay was utilized to measure cell proliferation and it was demonstrated that baicalin decreased the proliferative ability of the induced HSC-T6 cells (Fig. 2A). As a critical event in fibrosis is the upregulation of proteins, such as $\alpha$-SMA, the mRNA and protein expression levels of $\alpha$-SMA in activated HSC-T6 cells following treatment with different concentrations of baicalin for $48 \mathrm{~h}$ were determined. The mRNA and protein expression levels of $\alpha$-SMA were significantly decreased compared with the levels in the untreated group (Fig. 2B and C). Subsequently, the effect of baicalin on apoptosis and cell cycle progression was determined. It was demonstrated that baicalin treatment significantly increased the number of apoptotic cells (Fig. 2D and E). In addition, baicalin treatment resulted in a notable increase in the number of cells in $\mathrm{S}$ phase and a decrease in the number of cells in the G0/G1 phase compared with the numbers in the untreated group (Fig. 2F).

Baicalin decreases epithelial-to-mesenchymal transition (EMT) of activated HSC-T6 cells induced by PDGF-BB. Epithelial cells lose their polarity as a result of intercellular adhesion complexes changing their phenotypes. They may then move through the ECM like mesenchymal cells, and this process is termed EMT (28). Activated HSCs exhibit a significant elevation in mesenchymal and epithelial markers, which suggests that they undergo EMT (12). Therefore, the present study aimed to determine the effect of baicalin on the invasion and migration of induced HST-T6 cells. Treatment with baicalin significantly inhibited the motility and invasive ability of the induced HST-T6 cells in a dose-dependent manner compared with that observed in untreated cells $(\mathrm{P}<0.05$; Fig. 3). 

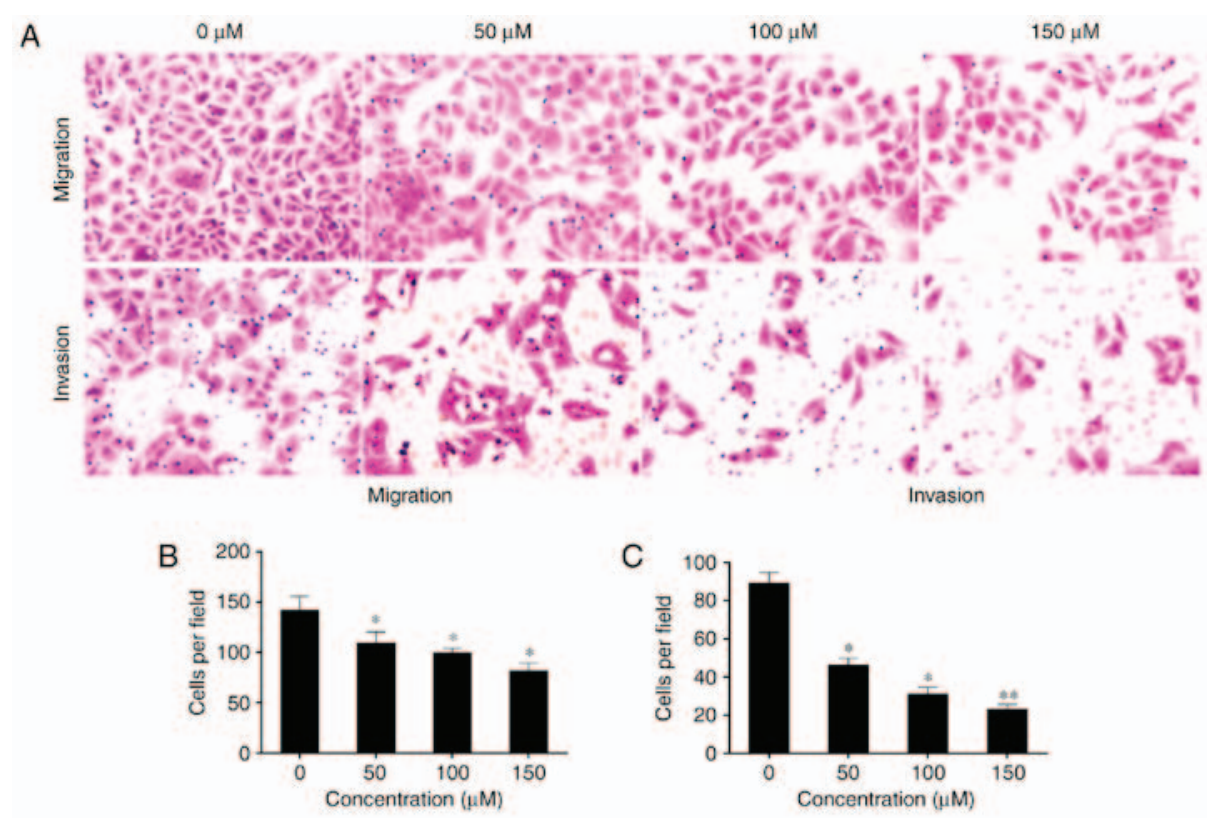

Figure 3. Baicalin inhibits the motility and invasive potential of PDGF-BB-induced HSC-T6 cells. (A) PDGF-BB-induced HSC-T6 cells were treated with baicalin at different concentrations $(0,50,100$ or $150 \mu \mathrm{M})$ and the migration and invasion rates of the cells were measured. Baicalin at 50,100 and 150 significantly inhibited the (B) migration (magnification, $\mathrm{x} 400$ ) and (C) invasion (magnification, $\mathrm{x} 400$ ) of PDGF-BB-induced HSC-T6 cells compared with untreated cells. However, even though the ability of the cells to migrate and invade decreased with the increase in baicalin concentration, no significant differences were observed between the different baicalin concentrations. ${ }^{*} \mathrm{P}<0.05$ and ${ }^{* *} \mathrm{P}<0.01$ vs. untreated cells. PDGF, platelet-derived growth factor.
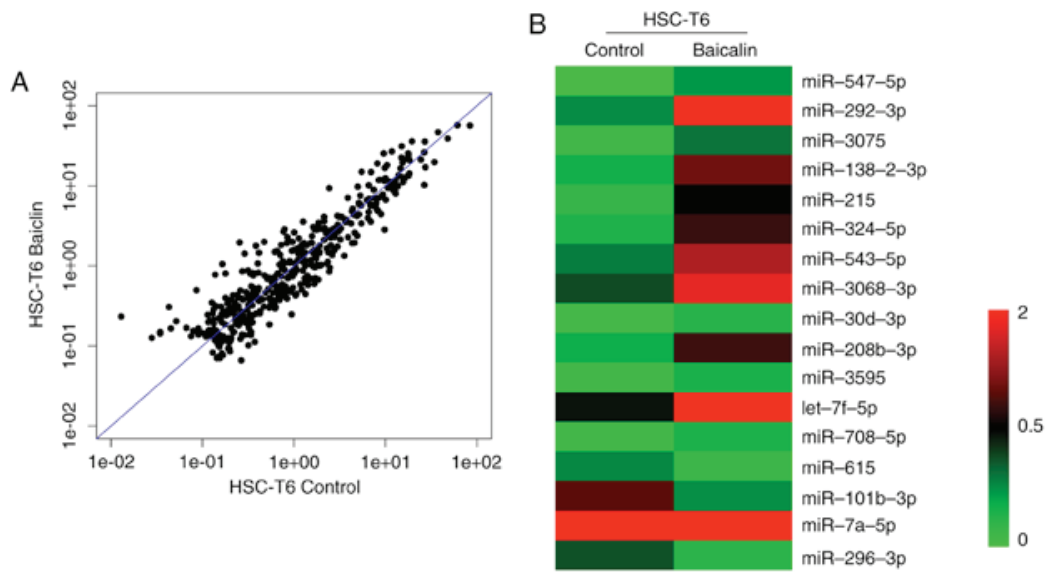

Figure 4. Analysis of miRNA expression profile using a one-color miRNA array. Comparison of differentially expressed miRNA in baicalin-treated platelet-derived growth factor-BB-induced HSC-T6 cells with untreated HSC-T6 cells. (A) Scatter plot of miRNA expression profiles. (B) Clustering of differentially expressed miRNA. miRNA, microRNA.

miR-3595 serves an important role in the anti-fibrotic effect of baicalin. To identify the miRNA involved in the anti-fibrotic effect of baicalin, miRNA expression profiles were compared between induced HSC-T6 cells treated with $100 \mu \mathrm{M}$ baicalin and untreated cells, using a one-color miRNA array. miR-547-5p, miR-296-3p and miR-3595 were dysregulated in the baicalin-treated group when compared with the control group (Fig. 4). To further validate the microarray data, the expression levels of miR-3595 were compared between the two groups of cells using RT-qPCR. As demonstrated in Fig. 5, miR-3595 was significantly upregulated in baicalin-treated cells compared to the level in the untreated cells $(\mathrm{P}<0.05$; Fig. 5B). In addition, the cell proliferation rate was rescued by miR-3595 inhibitor compared with that in the baicalin-treated group, as measured by a CCK8 assay (Fig. 5A). Cellular apoptosis and cell cycle effects of the miR-3395 inhibitor were also detected. As demonstrated in Fig. 5C and D, baicalin significantly induced cell apoptosis compared with the level in the control group, while the miR-3595 inhibitor reversed baicalin-induced cell apoptosis. Baicalin treatment induced an increase in the number of cells in S phase and decreased the number of cells in the G0/G1 phase compared with the control group; however, miR-3595 inhibitor reversed these baicalin-induced effects (Fig. 5E). Furthermore, miR-3595 inhibitor recovered the baicalin-induced inhibitory effects on cell migration and invasion (Fig. 6). These results suggest that inhibiting miR-3595 significantly suppressed the anti-fibrotic effect of baicalin.

To determine the role of miR-3595 on the anti-fibrotic effect of baicalin, the protein levels of $\alpha$-SMA, Col I, Col III, TGF- $\beta$ and desmin were measured. As demonstrated in Fig. 7, the expression 

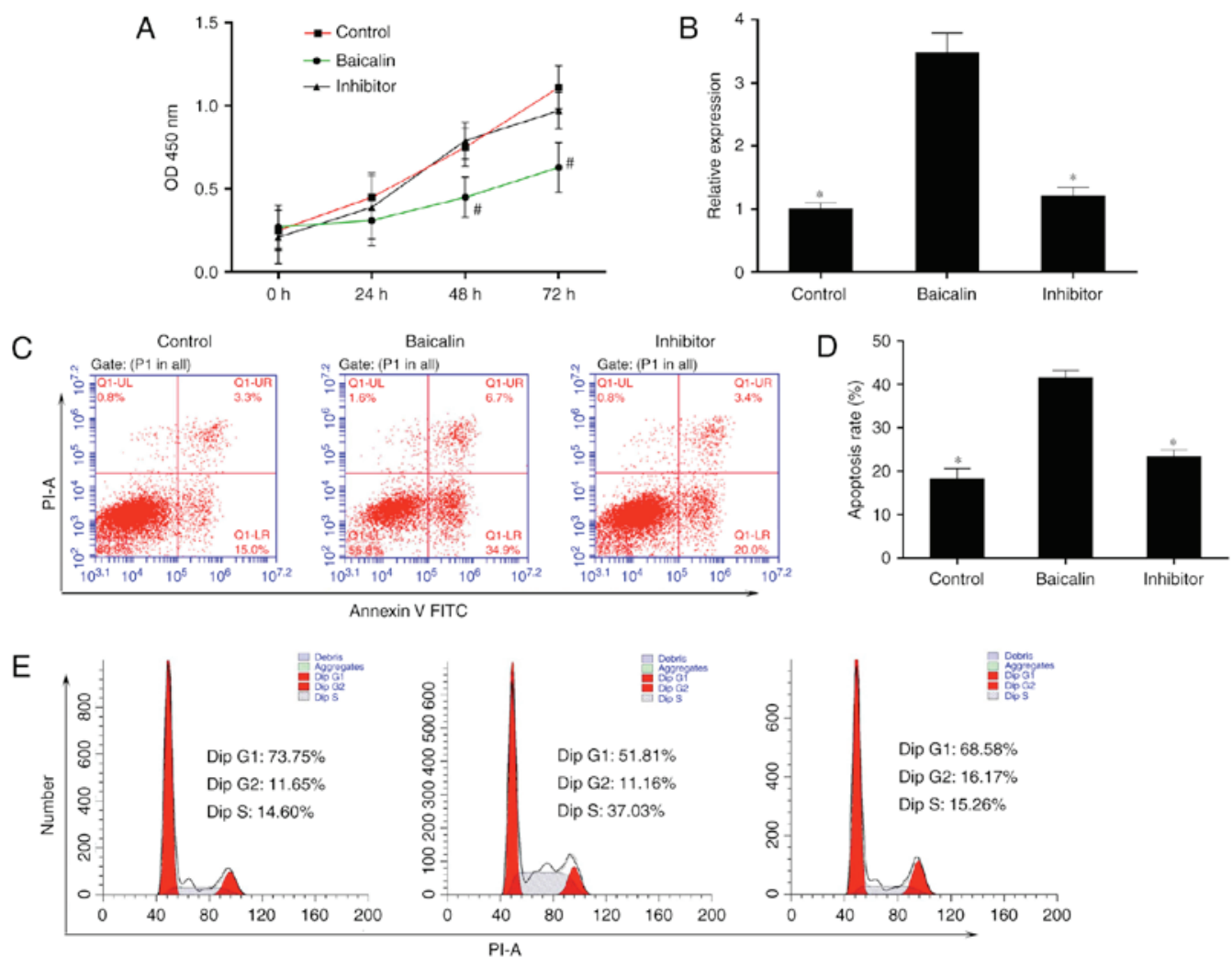

Figure 5. miR-3595 serves an important role in inhibiting cell proliferation and increasing apoptosis in PDGF-BB-induced HSC-T6 cells treated with baicalin. PDGF-BB-induced HSC-T6 cells were treated with baicalin at a concentration of $100 \mu \mathrm{M}$. The inhibitor group consisted of cells that were transfected with miR-3595 inhibitors in addition to treatment with baicalin. (A) A Cell Counting Kit- 8 assay was used to determine the cell proliferation every $24 \mathrm{~h}$ for 3 days. (B) The expression of miR-3595 in each group was determined by quantitative reverse transcription-quantitative polymerase chain reaction. (C and D) The apoptosis rate of HSC-T6 cells in each group was measured by flow cytometry. (E) Baicalin regulated the cell cycle of PDGF-BB-induced HSC-T6 cells through miR-3595. " $\mathrm{P}<0.05$ vs. control and inhibitor groups; " $\mathrm{P}<0.05$ vs. baicalin only-treated group. PDGF, platelet-derived growth factor; OD, optical density; PI, propidium iodide; FITC, fluorescein isothiocyanate.
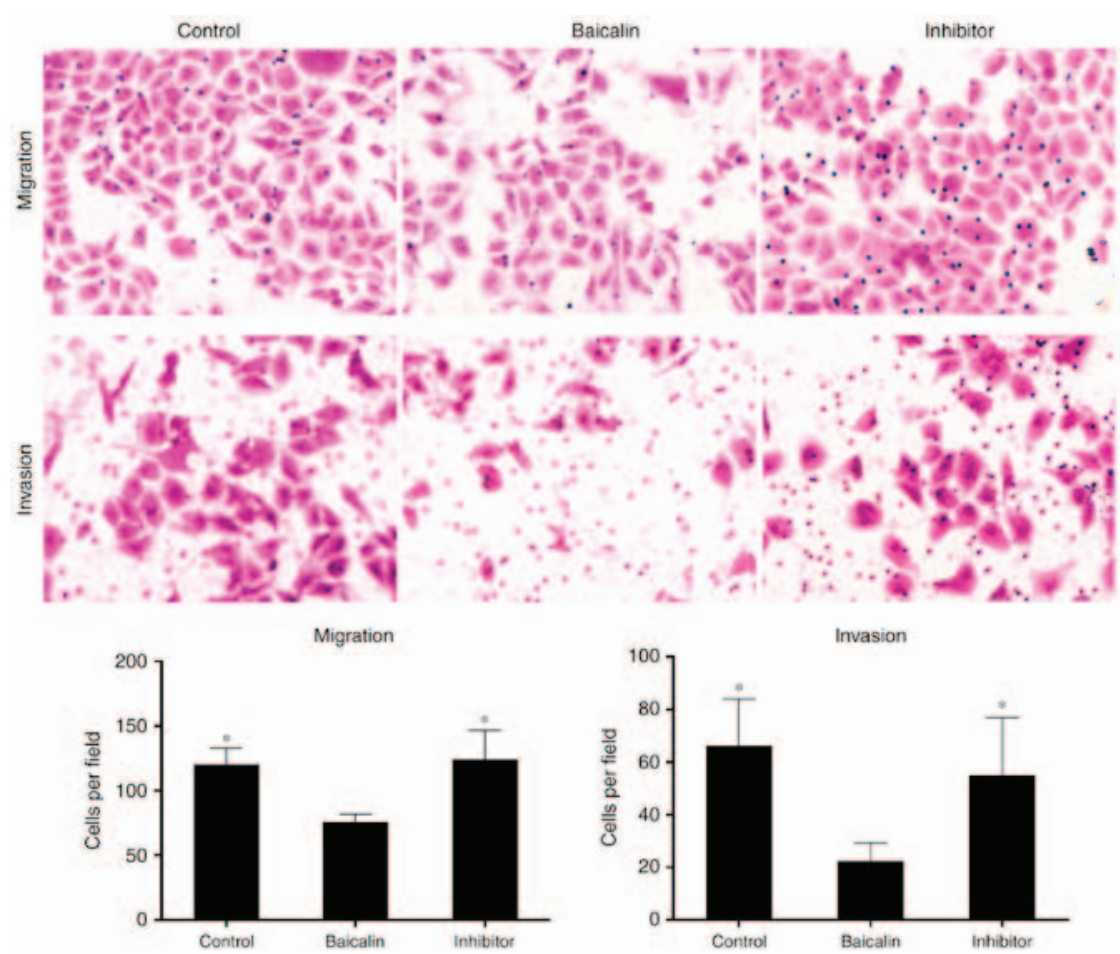

Figure 6. miR-3595 serves an important role in inhibiting the migration and invasion of PDGF-BB-induced HSC-T6 cells treated with baicalin. PDGF-BB-induced HSC-T6 cells were treated with $100 \mu \mathrm{M}$ baicalin. The cells in the inhibitor group were transfected with miR-3595 inhibitors in addition to treatment with baicalin. Representative numbers of cells undergoing migration or invasion was counted and captured (magnification, $\mathrm{x} 400$ ). ${ }^{*} \mathrm{P}<0.05$ vs. baicalin only-treated group. PDGF, platelet-derived growth factor. 
levels of these proteins in activated HCS-T6 cells treated with $100 \mu \mathrm{M}$ baicalin and miR-3595 inhibitor were similar to those in the activated HSC-T6 cells without any treatment, while the expression levels of these proteins in the baicalin-treated activated HCS-T6 cells were markedly decreased. Taken together, the present results suggest that miR-3595 regulates the anti-fibrotic effects of baicalin with respect to cell proliferation, apoptosis, invasion and migration, and fibrosis-related protein expression levels.

Effect of miR-3595 on baicalin-induced anti-fibrosis is through the regulation of ACSL4 expression. Previous studies indicate that the expression of ACSL4 is related to the synthesis of eicosanoid-CoA and the conversion of arachidonic acid into phosphatidyl ethanolamine, phosphatidyl inositol and triglyceride $(29,30)$, and that it serves a role in liver disease. Thus, it was hypothesized that ACSL4 is a direct miR-3595 target. The perfect complementation between the miR-3595 'seed' sequence and the potential 'recognition' sequences in the 3'UTR of ACSL4 were observed (Fig. 8A), suggesting that miR-3595 downregulates ACSL4 expression by inhibiting the translation of target mRNA. To confirm this hypothesis, the induced HSC-T6 cells were co-transfected with ACSL4-3'UTR luciferase reporters and miR-3595 mimics. Results demonstrated that miR-3595 significantly decreased the luciferase activity of cells transfected with ACSL4-WT-3'UTR reporter compared with the level in the NC group $(\mathrm{P}<0.05)$; however, transfection of the ACSL4-MUT-3'UTR had no significant effect on luciferase activity (Fig. 8B). The mRNA and protein expression levels of ACSL4 in HSC-T6 cells decreased significantly on treatment with $100 \mu \mathrm{M}$ baicalin compared with the level in the untreated group $(\mathrm{P}<0.05)$. These results indicate that miR-3595 negatively regulates ACSL4. To further validate these results, ACSL4 was overexpressed via a plasmid in HSC-T6 cells treated with $100 \mu \mathrm{M}$ baicalin. Results demonstrated that the forced expression of ACSL4 attenuated the anti-fibrotic effect of baicalin by significantly reducing and apoptosis of drug-treated induced HST-T6 cells $(\mathrm{P}<0.05)$, and increasing the proliferation, invasion and migration of induced HST-T6 cells $(\mathrm{P}<0.05)$, and increasing expression levels of fibrosis-related proteins (Figs. 9 and 10). Therefore, miR-3595 targets ACSL4, which is involved in the regulation of the anti-fibrotic effect of baicalin.

\section{Discussion}

Liver fibrosis is a wound healing response to a variety of stimuli (31,32). The progression of liver fibrosis leads to a number of pathological and biochemical changes, such as the distortion of normal structural architecture of the liver, resulting in metabolic abnormalities (33) or hepatocellular carcinoma (34). Accumulating evidence suggests that several cell types are involved in the development of liver fibrosis (35). However, the activation of HSCs is a particularly critical process in the pathogenesis of liver fibrosis. Following liver injury, HSCs increase the expression of $\alpha$-SMA, c-Myb, and myocyte enhancer factor-2, and acquire a myofibroblast-like phenotype $(35,36)$. A complex network of intracellular events occurs during the activation of HSCs (37-43). Thus, one anti-fibrotic therapy is the modulation of the proliferation, activation and apoptosis of HSCs.
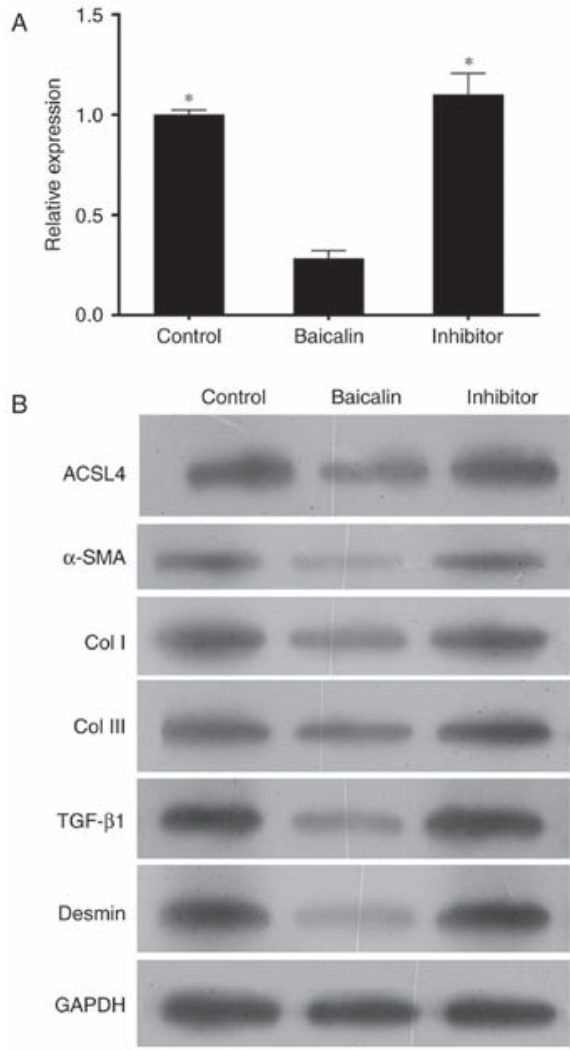

Figure 7. Western blot analysis of protein expression levels in activated hepatic stellate cells treated with miR-3595 inhibitors and baicalin. Platelet-derived growth factor-BB-induced HSC-T6 cells were treated with $100 \mu \mathrm{M}$ baicalin. The inhibitor group consisted of cells that were transfected with miR-3595 inhibitors in addition to baicalin. (A) Cells were harvested to analyze the mRNA expression level of ACSL4 by reverse transcription-quantitative polymerase chain reaction and (B) the protein expression levels of ACSL4, $\alpha$-SMA, Col I, Col III, TGF- $\beta 1$ and desmin by western blot analysis. ${ }^{*} \mathrm{P}<0.05$ vs. baicalin only-treated cells. ACSL4, long-chain-fatty-acid-CoA ligase 4; $\alpha$-SMA, $\alpha$-smooth muscle actin; TGF- $\beta 1$, transforming growth factor- $\beta 1$; Col, collagen.
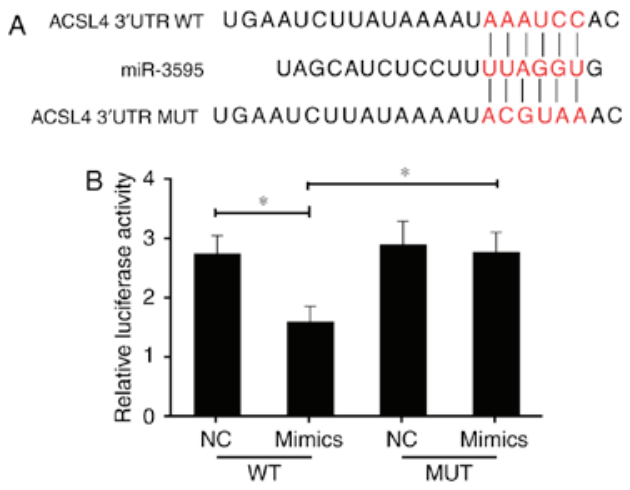

Figure 8. The anti-fibrosis effect of miR-3595 occurs through targeting ACSL4. (A) Sequence alignment between miR-3595 and the 3'UTR of human ACSL4 mRNA. The letters in red indicate the seed-mutated region. (B) Luciferase reporter assays demonstrated the effect of miR-3595 on the activity of the ACSL4 3'UTR and MUT ACSL4 3'UTR reporters. "P<0.05 as indicated. ACSL4, long-chain-fatty-acid-CoA ligase 4; UTR, untranslated region; WT, wild-type; MUT, mutant; NC, negative control.

The ideal anti-fibrotic agent should be liver-specific and have low hepatotoxicity; however, currently these agents are not commercially available (33). Hence, natural products 
A

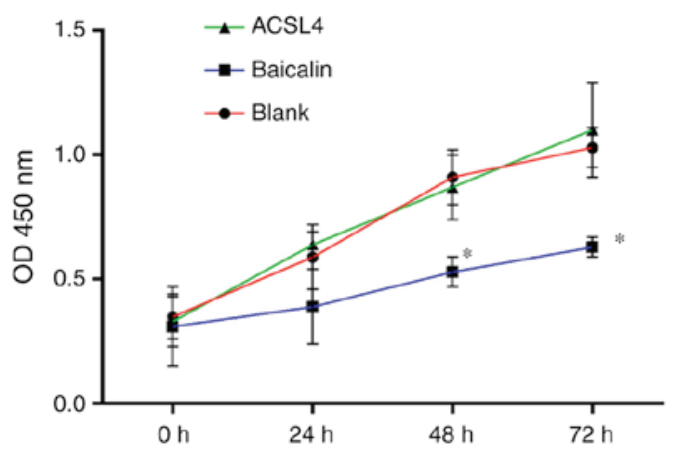

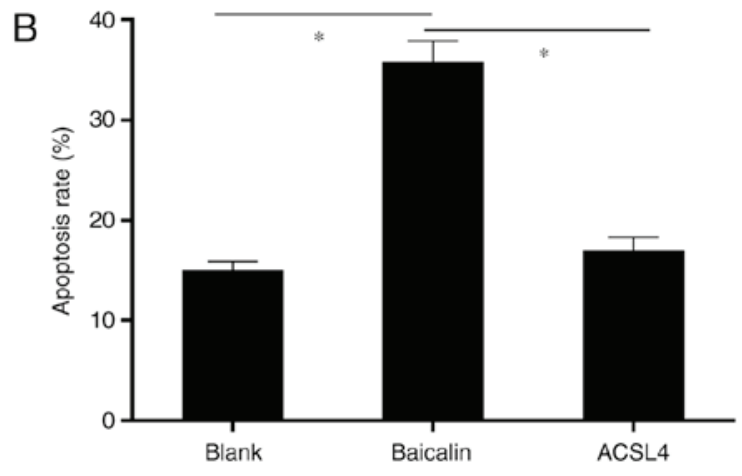

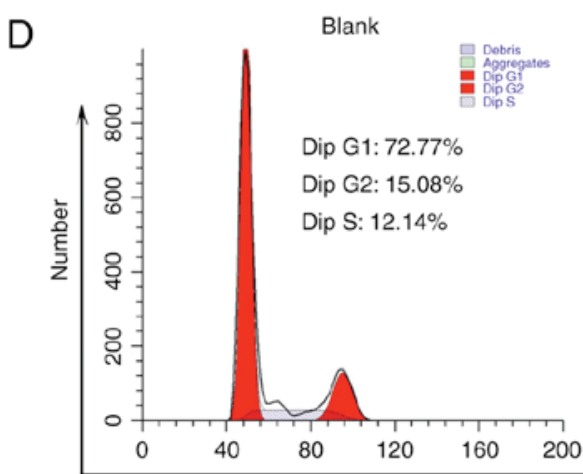

Baicalin

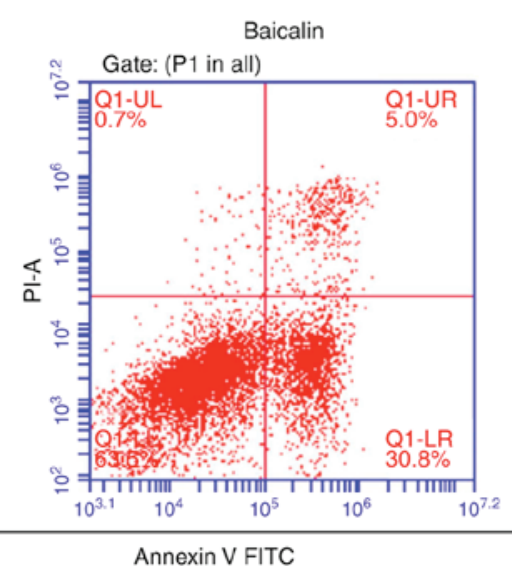

Annexin V FITC
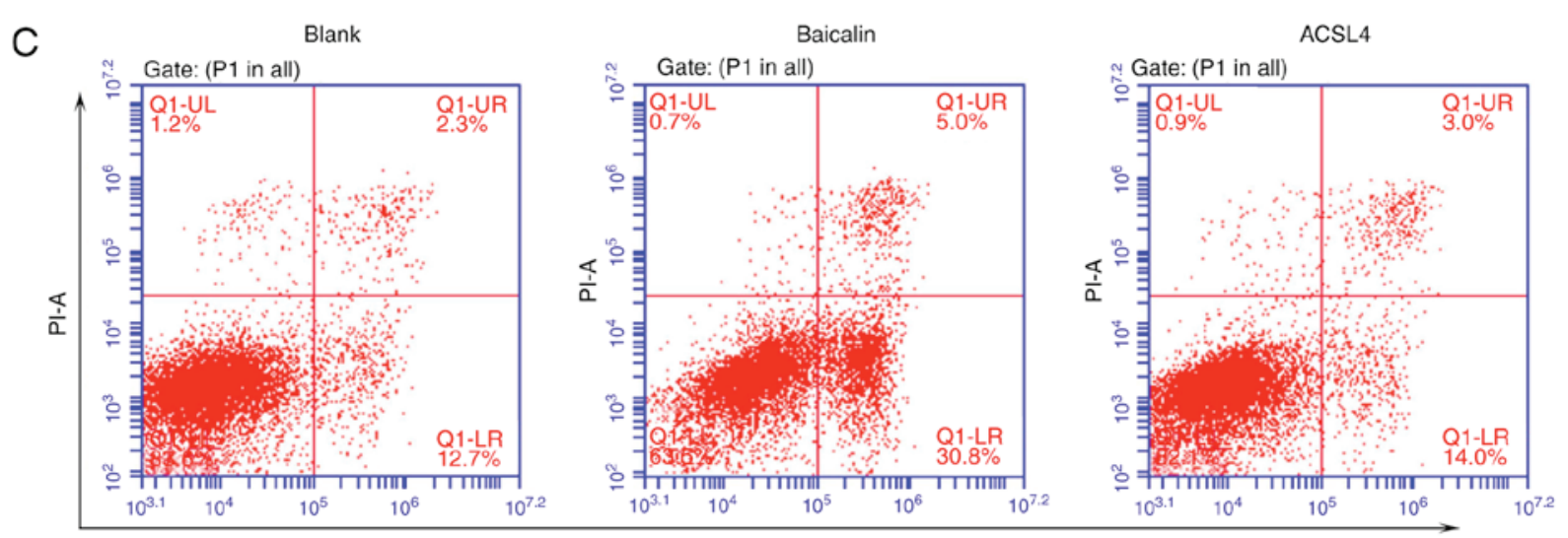
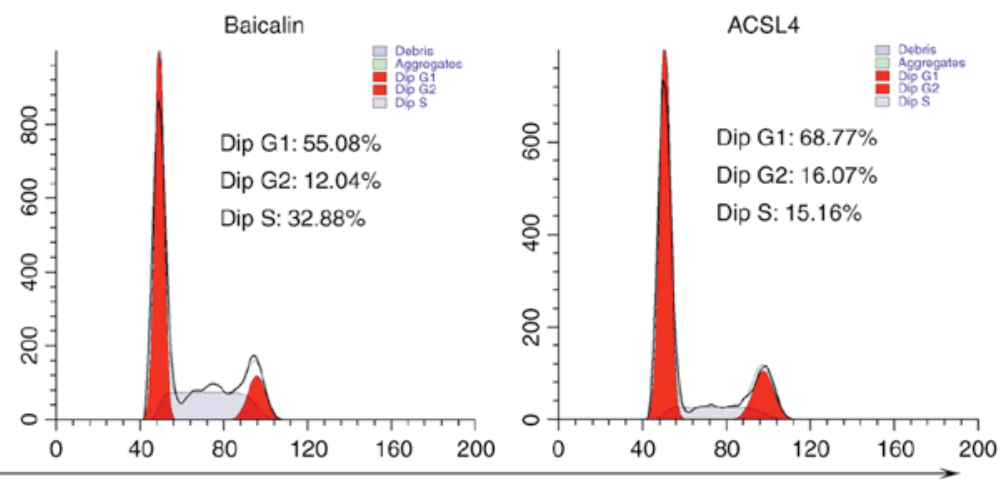

Figure 9. Exogenetic overexpression of ACSL4 attenuates the anti-fibrotic effect of baicalin on proliferation and apoptosis. Platelet-derived growth factor-BB-induced HSC-T6 cells were treated with $100 \mu \mathrm{M}$ baicalin. One group of cells was transfected with ACSL4-overexpressing plasmid in addition to baicalin. (A) A Cell Counting Kit-8 assay was used to determine cell proliferation every $24 \mathrm{~h}$ for 3 days. (B and C) The apoptosis rate for each group of HSC-T6 cells was measured by flow cytometry. (D) The forced expression of ACSL4 attenuated the anti-fibrotic effect of baicalin on the cell cycle. "P<0.05 vs. ACSL4 and control group; ${ }^{\#} \mathrm{P}<0.05$ vs. baicalin-treated group. ACSL4, long-chain-fatty-acid-CoA ligase 4; OD, optical density; PI, propidium iodide; FITC, fluorescein isothiocyanate.

and herbal medicines are potential therapies for hepatic fibrosis. Baicalin is a bioactive flavonoid with a multitude of pharmacological activities that include inhibiting the effects of several viruses (44-46), a variety of inflammatory diseases (47-49) and various types of cancer (50). Notably, previous studies have demonstrated that baicalin serves an important role in the fibrotic liver by reducing oxidative stress and shifting the balance of cytokines from pro-fibrotic to anti-fibrotic in experimental animal models $(13,51)$.

However, the mechanism of the anti-fibrotic effect of baicalin is not understood. To elucidate the anti-fibrotic function of baicalin and its possible mechanism, the present study treated activated HSC-T6 cells induced by PDGF-BB with baicalin at different concentrations $(50,100$ or $150 \mu \mathrm{M})$. It was revealed that baicalin reduced the proliferation, invasion and migration of these cells. Baicalin also reduced the expression levels of $\alpha$-SMA (a marker of activated HSCs), and increased the number of apoptotic cells, in a dose-dependent manner. These data suggested that baicalin inhibits the proliferation, apoptosis, invasion, migration and activation of PDGF-BB-treated HSCs.

miRNA have been implicated in various diseases, such as liver fibrosis, and several current therapeutic strategies involve the manipulation of miRNA levels (52). Thus, the present study aimed to verify whether baicalin regulated the expression 


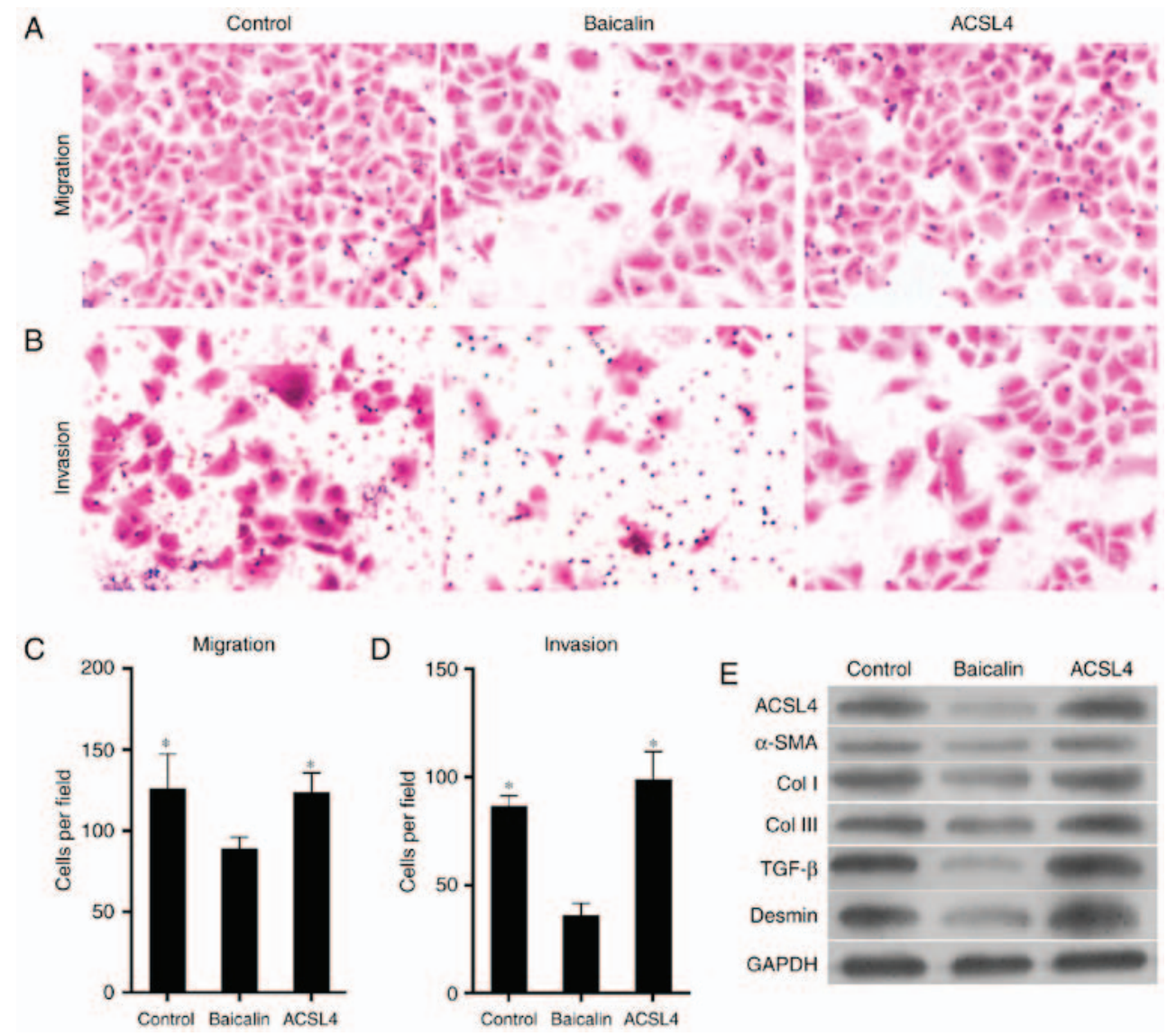

Figure 10. Exogenetic overexpression of ACSL4 attenuates the anti-fibrotic effect of baicalin on cell migration and invasion, and influences the expression levels of pro-fibrotic proteins. Platelet-derived growth factor-BB-induced HSC-T6 cells were treated with $100 \mu \mathrm{M}$ baicalin. One group of cells was transfected with ACSL4-overexpressing plasmid in addition to baicalin. Microscope images of cells undergoing (A) migration and (B) invasion (magnification, x400). Representative number of cells undergoing (C) migration and (D) invasion was counted. (E) Protein expression levels of fibrosis-promoting proteins, including ACSL4, $\alpha$-SMA, Col I, Col III, TGF- $\beta$ and desmin were verified by western blotting. ${ }^{*} \mathrm{P}<0.05$ vs. baicalin-treated group. ACSL4, long-chain-fatty-acid-CoA ligase 4; $\alpha$-SMA, $\alpha$-smooth muscle actin; TGF- $\beta$, transforming growth factor- $\beta$; Col, collagen.

of miRNA in induced HSC-T6 cells. miRNA profiling of baicalin-treated cells and untreated cells was performed, and the data indicated that some miRNA were differentially expressed between the two groups. One of these differentially expressed miRNA was miR-3595. The present study further confirmed the differential expression of miR-3595 using RT-qPCR. The present study, therefore, demonstrated that baicalin increases the expression of endogenous miR-3595. Furthermore, the present study indicated that silencing the expression of miR-3595 attenuated the anti-fibrotic effect of baicalin. These results suggested that miR-3595 upregulation serves an important role in the anti-fibrotic effect of baicalin. In humans, miRNA regulate gene expression by binding to the 3'UTR of mRNA or miRNA response elements, resulting in translational repression $(53,54)$.

The liver is the central organ involved in fatty acid (FA) homeostasis (55). ACSL4, a member of the ACSL family, catalyzes the cellular metabolism of polyunsaturated FA in different tissues (56-58). ACSL4 was recently demonstrated to have various functions in different cell lines (59). ACSL4 also promotes cell invasion by regulating the generation of eicosanoids in breast cancer (60). Through prediction and experimental validation, the present study indicated that ACSL4 was a direct target of miR-3595. Indeed, exogenous overexpression of ACSL4 suppressed the anti-fibrotic effect of baicalin in induced HSC-T6 cells. However, the relevance of the relationship between ACSL4 and fibrosis remains unclear.

Thus, it may be speculated that the anti-fibrotic effect of baicalin is associated with the miR-3593/ACSL 4 axis. Furthermore, the present study identified several differentially expressed miRNA that could be potential targets of baicalin. However, it is also possible that the anti-fibrotic effect of baicalin acts through signaling pathways other than miRNA-related ones. Baicalin may be a promising chemotherapy drug; however, further work is required to test this hypothesis.

In summary, the present findings suggest that baicalin inhibits the proliferation and activation observed in induced HSCs. One potential mechanism through which baicalin mediates its anti-fibrotic effect could be mediated via the increased expression of miR-3595, which leads to a decrease in the expression of ACSL4. Taken together, the present results demonstrate that baicalin may be a novel therapeutic in the treatment of hepatic fibrosis. To the best of our knowledge, the present study is the first to identify a role of miR-3593/ACSL4 in regulating liver fibrosis, specifically in the activation of HSCs.

\section{Competing interests}

The authors declare that they have no competing interests. 


\section{References}

1. Lee UE and Friedman SL: Mechanisms of hepatic fibrogenesis Best Pract Res Clinical Gastroenterol 25: 195-206, 2011.

2. Friedman SL: Mechanisms of hepatic fibrogenesis. Gastroenterology 134: 1655-1669, 2008.

3. Trappoliere M, Caligiuri A, Schmid M, Bertolani C, Failli P, Vizzutti F, Novo E, di Manzano C, Marra F, Loguercio C and Pinzani M: Silybin, a component of sylimarin, exerts anti-inflammatory and anti-fibrogenic effects on human hepatic stellate cells. J Hepatol 50: 1102-1111, 2009.

4. Bataller R and Brenner DA: Liver fibrosis. J Clin Invest 115: 209-218, 2005

5. Popov Y and Schuppan D: Targeting liver fibrosis: Strategies for development and validation of antifibrotic therapies Hepatology 50: 1294-1306, 2009.

6. Friedman SL: Hepatic stellate cells: Protean, multifunctional, and enigmatic cells of the liver. Physiol Rev 88: 125-172, 2008.

7. Szabo G and Bala S: MicroRNAs in liver disease. Nat Rev Gastroenterol Hepatol 10: 542-552, 2013.

8. Wong L, Yamasaki G, Johnson RJ and Friedman SL: Induction of beta-platelet-derived growth factor receptor in rat hepatic lipocytes during cellular activation in vivo and in culture. J Clin Invest 94: 1563-1569, 1994

9. Wu CI, Hoffman JA, Shy BR, Ford EM, Fuchs E, Nguyen H and Merrill BJ: Function of Wnt $/ \beta$-catenin in counteracting Tcf3 repression through the Tcf3- $\beta$-catenin interaction. Development 139: 2118-2129, 2012.

10. Takase S, Takada A, Yasuhara M, Sato H and Matsuda Y: Effects of malotilate treatment on the serum markers of hepatic fibrogenesis in liver cirrhosis. Gastroenterol Jpn 23: 639-645, 1988.

11. Fu Y, Zheng S, Lin J, Ryerse J and Chen A: Curcumin protects the rat liver from CCl4-caused injury and fibrogenesis by attenuating oxidative stress and suppressing inflammation. Mol Pharmacol 73: 399-409, 2008.

12. Chen SR, Chen XP, Lu JJ, Wang Y and Wang YT: Potent natural products and herbal medicines for treating liver fibrosis. Chin Med 10: 7, 2015.

13. Peng XD, Dai LL, Huang CQ, He CM and Chen LJ: Correlation between anti-fibrotic effect of baicalin and serum cytokines in rat hepatic fibrosis. World J Gastroenterol 15: 4720-4725, 2009.

14. de Oliveira MR, Nabavi SF, Habtemariam S, Erdogan Orhan I, Daglia M and Nabavi SM: The effects of baicalein and baicalin on mitochondrial function and dynamics: A review. Pharmacol Res 100: 296-308, 2015.

15. Yang MD, Chiang YM, Higashiyama R, Asahina K, Mann DA, Mann J, Wang CC and Tsukamoto H: Rosmarinic acid and baicalin epigenetically derepress peroxisomal proliferator-activated receptor gamma in hepatic stellate cells for their antifibrotic effect. Hepatology 55: 1271-1281, 2012.

16. Zhu QJ: Research advances on baicalin and baicalein as potential therapeutic agents for fibrotic disease. Zhongguo Zhong Yao Za Zhi 42: 1271-1276, 2017 (In Chinese).

17. Meng F, Wang K, Aoyama T, Grivennikov SI, Paik Y, Scholten D, Cong M, Iwaisako K, Liu X, Zhang M, et al: Interleukin-17 signaling in inflammatory, Kupffer cells, and hepatic stellate cells exacerbates liver fibrosis in mice. Gastroenterology 143 765-776.e3, 2012.

18. Kong X, Feng D, Wang H, Hong F, Bertola A, Wang FS and Gao B: Interleukin-22 induces hepatic stellate cell senescence and restricts liver fibrosis in mice. Hepatology 56: 1150-1159, 2012.

19. Lee RC, Feinbaum RL and Ambros V: The C. elegans heterochronic gene lin-4 encodes small RNAs with antisense complementarity to lin-14. Cell 75: 843-854, 1993

20. Filipowicz W, Bhattacharyya SN and Sonenberg N: Mechanisms of post-transcriptional regulation by microRNAs: Are the answers in sight? Nat Rev Genet 9: 102-114, 2008.

21. Teng KY and Ghoshal K: Role of noncoding RNAs as biomarker and therapeutic targets for liver fibrosis. Gene Expr 16: 155-162, 2015.

22. Lewin TM, Kim JH, Granger DA, Vance JE and Coleman RA: Acyl-CoA synthetase isoforms 1,4 , and 5 are present in different subcellular membranes in rat liver and can be inhibited independently. J Biol Chem 276: 24674-24679, 2001.

23. Lewin TM, Van Horn CG, Krisans SK and Coleman RA: Rat liver acyl-CoA synthetase 4 is a peripheral-membrane protein located in two distinct subcellular organelles, peroxisomes, and mitochondrial-associated membrane. Arch Biochem Biophys 404: 263-270, 2002.
24. Yan S, Yang XF, Liu HL, Fu N, Ouyang Y and Qing K: Long-chain acyl-CoA synthetase in fatty acid metabolism involved in liver and other diseases: An update. World J Gastroenterol 21: 3492-3498, 2015.

25. Liang YC, Wu CH, Chu JS, Wang CK, Hung LF, Wang YJ, Ho YS, Chang JG and Lin SY: Involvement of fatty acid-CoA ligase 4 in hepatocellular carcinoma growth: Roles of cyclic AMP and p38 mitogen-activated protein kinase. World J Gastroenterol 11: 2557-2563, 2005.

26. Lin X, Kong LN, Huang C, Ma TT, Meng XM, He Y, Wang QQ and Li J: Hesperetin derivative-7 inhibits PDGF-BB-induced hepatic stellate cell activation and proliferation by targeting Wnt/ $\beta$-catenin pathway. Int Immunopharmacol 25: 311-320, 2015.

27. Livak KJ and Schmittgen TD: Analysis of relative gene expression data using real-time quantitative PCR and the 2(-Delta Delta C(T)) method. Methods 25: 402-408, 2001

28. Acloque H, Adams MS, Fishwick K, Bronner-Fraser M and Nieto MA: Epithelial-mesenchymal transitions: The importance of changing cell state in development and disease. J Clin Invest 119: 1438-1449, 2009.

29. Golej DL, Askari B, Kramer F, Barnhart S, Vivekanandan-Giri A, Pennathur S and Bornfeldt KE: Long-chain acyl-CoA synthetase 4 modulates prostaglandin $\mathrm{E}(2)$ release from human arterial smooth muscle cells. J Lipid Res 52: 782-793, 2011.

30. Cooke M, Orlando U, Maloberti P, Podestá EJ and Cornejo Maciel F: Tyrosine phosphatase SHP2 regulates the expression of acyl-CoA synthetase ACSL4. J Lipid Res 52: 1936-1948, 2011

31. Schuppan D: Structure of the extracellular matrix in normal and fibrotic liver: Collagens and glycoproteins. Semin Liver Dis 10: 1-10, 1990.

32. Anthony PP, Ishak KG, Nayak NC, Poulsen HE, Scheuer PJ and Sobin LH: The morphology of cirrhosis. Recommendations on definition, nomenclature, and classification by a working group sponsored by the World Health Organization. J Clin Pathol 31: 395-414, 1978.

33. Mormone E, George $\mathrm{J}$ and Nieto N: Molecular pathogenesis of hepatic fibrosis and current therapeutic approaches. Chem Biol Interact 193: 225-231, 2011

34. Han YP, Zhou L, Wang J, Xiong S, Garner WL, French SW and Tsukamoto $\mathrm{H}$ : Essential role of matrix metalloproteinases in interleukin-1-induced myofibroblastic activation of hepatic stellate cell in collagen. J Biol Chem 279: 4820-4828, 2004.

35. Gressner AM: Transdifferentiation of hepatic stellate cells (Ito cells) to myofibroblasts: A key event in hepatic fibrogenesis. Kidney Int (Suppl 54): S39-S45, 1996.

36. Woodhoo A, Iruarrizaga-Lejarreta $\mathrm{M}$, Beraza $\mathrm{N}$, García-Rodríguez JL, Embade N, Fernández-Ramos D, Martínez-López N, Gutiérrez-De Juan V, Arteta B, Caballeria J, et al: Human antigen R contributes to hepatic stellate cell activation and liver fibrosis. Hepatology 56: 1870-1882, 2012.

37. Fickert P, Fuchsbichler A, Moustafa T, Wagner M, Zollner G, Halilbasic E, Stöger U, Arrese M, Pizarro M, Solís N, et al: Farnesoid $\mathrm{X}$ receptor critically determines the fibrotic response in mice but is expressed to a low extent in human hepatic stellate cells and periductal myofibroblasts. Am J Pathol 175: 2392-2405, 2009.

38. Sharvit E, Abramovitch S, Reif S and Bruck R: Amplified inhibition of stellate cell activation pathways by PPAR-gamma, RAR and RXR agonists. PloS One 8: e76541, 2013.

39. Ding N, Yu RT, Subramaniam N, Sherman MH, Wilson C, Rao R, Leblanc M, Coulter S, He M, Scott C, et al: A vitamin D receptor/SMAD genomic circuit gates hepatic fibrotic response. Cell 153: 601-613, 2013.

40. Li T, Eheim AL, Klein S, Uschner FE, Smith AC, BrandonWarner E, Ghosh S, Bonkovsky HL, Trebicka J and Schrum LW: Novel role of nuclear receptor Rev-erba in hepatic stellate cell activation: Potential therapeutic target for liver injury. Hepatology 59: 2383-2396, 2014.

41. Beaven SW, Wroblewski K, Wang J, Hong C, Bensinger S, Tsukamoto $\mathrm{H}$ and Tontonoz $\mathrm{P}$ : Liver $\mathrm{X}$ receptor signaling is a determinant of stellate cell activation and susceptibility to fibrotic liver disease. Gastroenterology 140: 1052-1062, 2011.

42. Zhu NL, Asahina K, Wang J, Ueno A, Lazaro R, Miyaoka Y, Miyajima A and Tsukamoto $\mathrm{H}$ : Hepatic stellate cell-derived delta-like homolog 1 (DLK1) protein in liver regeneration. J Biol Chem 287: 10355-10367, 2012. 
43. Delgado I,Carrasco M, Cano E, Carmona R, García-Carbonero R, Marín-Gómez LM, Soria B, Martín F, CanoDA, Muñoz-Chápuli R and Rojas A: GATA4 loss in the septum transversum mesenchyme promotes liver fibrosis in mice. Hepatology 59: 2358-2370, 2014.

44. Baylor NW, Fu T, Yan YD and Ruscetti FW: Inhibition of human $\mathrm{T}$ cell leukemia virus by the plant flavonoid baicalin (7-glucuronic acid, 5,6-dihydroxyflavone). J Infect Dis 165: 433-437, 1992.

45. Li BQ, Fu T, Dongyan Y, Mikovits JA, Ruscetti FW and Wang JM: Flavonoid baicalin inhibits HIV-1 infection at the level of viral entry. Biochem Biophys Res Commun 276: 534-538, 2000.

46. Zeng Y, Song C, Ding X, Ji X, Yi L and Zhu K: Baicalin reduces the severity of experimental autoimmune encephalomyelitis. Braz J Med Biol Res 40: 1003-1010, 2007.

47. Lin CC and Shieh DE: The anti-inflammatory activity of Scutellaria rivularis extracts and its active components, baicalin, baicalein and wogonin. Am J Chin Med 24: 31-36, 1996.

48. Kubo M, Matsuda H, Tanaka M, Kimura Y, Okuda H, Higashino M, Tani T, Namba K and Arichi S: Studies on Scutellariae radix. VII. Anti-arthritic and anti-inflammatory actions of methanolic extract and flavonoid components from Scutellariae radix. Chem Pharm Bull (Tokyo) 32: 2724-2729, 1984.

49. Zhang XP, Tian H, Lai YH, Chen L, Zhang L, Cheng QH, Yan W, Li Y, Li QY, He Q and Wang F: Protective effects and mechanisms of Baicalin and octreotide on renal injury of rats with severe acute pancreatitis. World J Gastroenterol 13: 5079-5089, 2007.

50. Ikezoe T, Chen SS, Heber D, Taguchi H and Koeffler HP: Baicalin is a major component of PC-SPES which inhibits the proliferation of human cancer cells via apoptosis and cell cycle arrest. Prostate 49: 285-292, 2001.

51. Sun H, Che QM, Zhao X and Pu XP: Antifibrotic effects of chronic baicalein administration in a CCl4 liver fibrosis model in rats. Eur J Pharmacol 631: 53-60, 2010.

52. Hyun J and Jung Y: MicroRNAs in liver fibrosis: Focusing on the interaction with hedgehog signaling. World J Gastroenterol 22 6652-6662, 2016.
53. Akhtar MM, Micolucci L, Islam MS, Olivieri F and Procopio AD: Bioinformatic tools for microRNA dissection. Nucleic Acids Res 44: 24-44, 2016

54. Ambros V: microRNAs: Tiny regulators with great potential. Cell 107: 823-826, 2001

55. Babin PJ and Gibbons GF: The evolution of plasma cholesterol: Direct utility or a 'spandrel' of hepatic lipid metabolism? Prog Lipid Res 48: 73-91, 2009.

56. Soupene E and Kuypers FA: Mammalian long-chain acyl-CoA synthetases. Exp Biol Med (Maywood) 233: 507-521, 2008.

57. Lopes-Marques M, Cunha I, Reis-Henriques MA, Santos MM and Castro LF: Diversity and history of the long-chain acyl-CoA synthetase (Acsl) gene family in vertebrates. BMC Evol Biol 13: 271,2013

58. Kang MJ, Fujino T, Sasano H, Minekura H, Yabuki N, Nagura H, Iijima $\mathrm{H}$ and Yamamoto TT: A novel arachidonate-preferring acyl-CoA synthetase is present in steroidogenic cells of the rat adrenal, ovary, and testis. Proc Natl Acad Sci USA 94: 2880-2884, 1997.

59. Doll S, Proneth B, Tyurina YY, Panzilius E, Kobayashi S, Ingold I, Irmler M, Beckers J, Aichler M, Walch A, et al: ACSL4 dictates ferroptosis sensitivity by shaping cellular lipid composition. Nat Chem Biol 13: 91-98, 2017.

60. Orlando UD, Garona J, Ripoll GV, Maloberti PM, Solano ÁR, Avagnina A, Gomez DE, Alonso DF and Podestá EJ: The functional interaction between Acyl-CoA synthetase 4,5-lipooxygenase and cyclooxygenase- 2 controls tumor growth: A novel therapeutic target. PloS One 7: e40794, 2012.

This work is licensed under a Creative Commons Attribution-NonCommercial-NoDerivatives 4.0 International (CC BY-NC-ND 4.0) License. 